\title{
Jorge Americano*.
}

\author{
Sílvio Rodrigues \\ Catedrático de Direito Civil na Faculdade de \\ Direito da Universidade de São Paulo.
}

Estamos hoje aqui reunidos, 30 dias após sua morte, para examinarmos ràpidamente a vida de Jorge AmEricano, figura humana de extraordinário colorido, de um lado com o propósito de retirar, da análise de seu comportamento nesta terra, a lição que uma existência digna apresenta e de outro com o intuito de homenagear um grande morto.

Mestre insigne perdeu nossa casa, que não mais verá passar, por estas arcadas, a figura altaneira do jurista emérito, que a amou como ninguém a amou e a dignificou como poucos! Homem ilustre perdeu esta cidade onde Jorge Americano nasceu, viveu e morreu e que por ela, com seu entusiasmo e patriotismo, deu mais do que lhe era reclamado, pois deu todo seu amor e sua dedicação! Figura curiosa perdeu êste país, pois, espírito de mil facetas interessantes, o escritor, o artista, o jurisconsulto, o advogado, o cronista de sua terra, o sociólogo se fundiam em uma única pessoa, irradiando uma simpatia contagiante, sujeita a uma discreta humildade! Grande perda sofremos todos nós, seus alunos e seus amigos, que não mais sentiremos, em nossas mãos, a mão amiga e cheia de calor humano, que nos aquecia o coração! Grande perda!

*. Discurso proferido na sessão solene da Congregação, realizada em honra do Prof. Jorge Americano, no trigésimo dia de seu falecimento, a 6 de março de 1969. 
Nasceu Jorge Americano na cidade de São Paulo, no dia 25 de agôsto de 1891, filho do Coronel Luiz Americano e de d. Amélia Cardoso Americano. Procedia de ilustre familia brasileira, e se foi apenas a segunda geração a portar o honrado apelido, isso se deve a peculiar circunstância. Seu pai o Coronel Luiz Americano, alistando-se como voluntário na Guerra do Paraguai, adotou o nôvo sobrenome para evitar que alguma gestão da família o pudesse impedir de levar a cabo sua patriótica deliberação de lutar naquele conflito.

Depois de fazer seus estudos primários na Escola Modêlo Caetano de Campos, da Praça da República, ingressou o querido mestre no Ginásio Estadual de São Paulo e ali foi aluno dos mais destacados. Curioso observar, desde logo sua nítida propensão para as ciências sociais a par de seu menor pendor para as chamadas ciências matemáticas. Em seu certificado de promoção da segunda para a terceira série do curso secundário, ao lado de 6 distinções em línguas, geografia e desenho, encontra-se um "simplesmente" cinco, em matemática.

Em março de 1908, com 17 anos, requer Jorge AmeriCANo, do Diretor da Academia de Direito, sua inscrição no primeiro ano do curso de ciências jurídicas e sociais e sua matrícula é deferida.

Se nos três primeiros anos do curso de bacharelado é aluno de menor realce, em virtude de sua infirme saúde na ocasião, nos últimos dois anos passa a ser estudante destacado e sua aprovação é com nota $9 \mathrm{em}$ tôdas as disciplinas.

Em 1912 forma-se em direito e no dia 14 de dezembro dêsse ano cola o grau de bacharel.

Munido de seu diploma o jovem advogado parte para a luta. Tem 21 anos de idade, é moço de porte elegante, formosas feições, e a modéstia da fortuna familiar não o impede de ser recebido pela melhor gente da cidade, a quem a sua linhagem, sua educação, sua conversa agil e espirituosa, seduzem e cativam. Traz no peito algumas 
ambições, uma delas, afagada com muita discreção e timidez, é a de voltar para o velho convento franciscano e tornar-se professor da Academia. Dez anos depois fará sua primeira tentativa para consolidar tal aspiração.

Ao sair da escola conserva durante um tempo o emprêgo de escriturário do Tesouro de São Paulo, para o qual fôra promovido em 1910, depois de haver sido admitido em 1908 como auxiliar extranumerário. Logo mais, entretanto, em 1913, é convidado pelo Secretário da Fazenda, para ser seu oficial de Gabinete, função que exerce por pouco tempo pois, nesse mesmo ano, assume o cargo de procurador fiscal interino.

A carreira profissional marcha lentamente e no ano de 1915 o bacharel Jorge Americano ingressa no Ministério Público, sendo nomeado promotor público na cidade de Bebedouro de onde, em 1918, é promovido para a Comarca de Atibaia; exonera-se, a pedido, do cargo no início de 1919.

Foram anos de grande felicidade aquêles. É que no dia 11 de setembro de 1917 meu querido mestre se casara com d. Maria Rafaela de Paula Souza, formosa moça de muitas virtudes, procedente de ilustre família paulista. Ela o acompanha a Bebedouro, depois à Atibaia. Finalmente o casal regressa a São Paulo em 1921. Anos felizes aquêles, interrompidos por uma grande desgraça. A morte do primogênito do casal, ocorrida nessa ocasião. Tal circunstância veio, talvez, provocar o aparecimento ou agravar a existência de séria e persistente moléstia que acompanhará d. Maria Rafaela por tôda a vida.

A conselho do médico que lhe assiste a espôsa, e que lhe recomenda a busca de melhor clima, muda-se Jorge Americano, no ano de 1921, para a cidade de Santos onde instala sua banca de advocacia. Seguem-se anos de bastante trabalho e de muito estudo, em que o intelectual, de cêrca de 30 anos acalenta a velha ambição e prepara sua carreira universitária.

O primeiro passo no sentido de encetá-la é ensaiado em fins de dezembro de 1922, ocasião em que o mestre 
requer sua inscrição ao concurso aberto para preenchimento da vaga de professor substituto da 7.a Secção desta Faculdade, secção essa que compreendia, entre outras afins, a disciplina de Direito Civil.

$\mathrm{O}$ concurso não se realizou por haver o Govêrno $\mathrm{Fe}$ deral, através do aviso de 17/1/1923, do Ministério da Justiça, determinado a sua suspensão.

Não desanima o jovem bacharel e no dia 27 de outubro de 1925, contando 34 anos, se inscreve simultâneamente em dois concursos; inscreve-se no concurso para livre docente de Direito Civil - $1 .^{\mathrm{a}}$ cadeira do $3 .^{\circ}$ ano, e no concurso para livre docente de Direito Judiciário Civil $-3 .^{a}$ cadeira do $4 .^{\circ}$ ano. Para o primeiro concurso apresentou dissertação sôbre a tese. "Como se aplica, nos acidentes de trabalho, o conceito de Ato ilícito"; e para o concurso de processo a monografia intitulada: "É cabível a ação Pauliana para revogação de hipotecas celebradas em fraude de credores?"

Já então Jorge Americano se tornara nome conhecido nas letras jurídicas pátrias, em virtude da publicação de duas obras que se tornaram clássicas no direito nacional: a primeira delas, "A ação rescisória dos julgados no Direito Brasileiro", alcançou grande repercussão por disciplinar, de maneira extremamente lógica e inteligente, matéria até então objeto de larga controvérsia; a segunda, obra "O abuso do direito no exercício da demanda", trazia análise profunda da teoria do abuso de direito, entre nós de pequena difusão na época, e da repercussão dessa teoria no campo do processo, onde se fixava um limite para a atividade do litigante, além do qual sua atitude, mesmo que não contrária à lei, se tornava ilícita, por abusiva.

Estes concursos também não se realizam porque logo a seguir abre-se vaga para uma das cadeiras de direito civil desta Escola. E assim, em outubro de 1926, Jorge AmeriCANo requer sua inscrição para o concurso à cátedra, trazendo como principal título as obras já publicadas, às quais, no intervalo, acrescentara uma outra, intitulada "Processo Civil e Comercial no Direito Brasileiro". 
Falou-me, o mestre, muitas vêzes dêsse concurso, em que concorreu com outros ilustres juristas brasileiros e no qual, embora classificado, não o foi em primeiros lugar, assim não tirando a cátedra.

Ouço-o ainda, com sua voz pausada, a contar-me que no dia da argüição saíra madrugada de casa, em Santos, vestindo casaca sob uma pesada capa de chuva e de trem, depois de taxi, dirigira-se a estas Arcadas, no meio de grande calor, para enfrentar o destino. Este, sem embargo do mérito inescondivel de seus ilustres adversários, não foi liberal para com o meu mestre. À época, o regime dos concursos era diverso e tôda a Congregação dava nota às provas, daí resultando a classificação e a média dos candidatos. Um dos examinadores, que meu mestre dizia seu desafeto, dava-lhe zero em provas que outros mestres lhe haviam conferido altas notas, fazendo, assim, com que a sua média caísse. Nunca me disse que ganharia o concurso se menor fôsse a parcialidade daquele gratuito inimigo. Mas, ressentia-se de tal tratamento.

Outro aspecto curioso dessas provas, que merece ser ressaltado, diz respeito às teses apresentadas. Àquêle tempo os candidatos à cátedra deviam apresentar duas dissertacões. Uma da escolha do candidato, e outra cujo tema era fixado pela Congregação. Esta escolheu como tema obrigatório "A posse dos Direitos Pessoais".

JorgF Americano então esposava a opinião, hoje prevalecente entre os juristas pátrios, de serem os direitos pessoais insusceptíveis de posse, instituto cujo campo específico é o dos direitos reais. De modo que, em seu espírito, surgiu desde logo séria dúvida. Não gostaria de dar a seu livro o nome "Posse dos Direitos Pessoais", quando ia combater tal tese; pois poderia enganar seu eventual leitor; por outro lado, apresentar a monografia com outro nome, poderia provocar uma recusa de inscrição por falta de um requisito para ela indispensável, ou seja, a elaboração de monografia sôbre tema fixado pela Congregação. 
Correndo todos os riscos Jorge Americano preferiu a $1 .^{\text {a }}$ alternativa e a monografia que apresentou, aliás livro extraordiniário sôbre o Instituto, chama-se "Dos Direitos que se exteriorizam pela Posse".

Havendo conquistado a docência livre de Direito Civil da Faculdade, a carreira do jovem estudioso agora ràpidamente se acelera.

Ainda nesse ano de 1927 é Jorge Americano convidado pela direção do Partido Republicano Paulista para disputar o mandado de deputado estadual, pelo $100^{\circ}$ distrito. A despeito de lhe haverem assegurado a eleição, por fôrça da conhecida maioria do partido, o escrupuloso candidato fêz campanha eleitoral para conhecer o eleitorado, coisa de um certo modo inusitada "àquela" época. Eleito em 1927, foi reeleito em 1928.

Por essa ocasião fêz parte da Comissão Organizadora do Projeto de Código de Processo Civil do Estado de São Paulo, onde, sob a presidência do grande Costa Manso, trabalhou quase dois anos. Dessa tarefa resultou um extraordinário trabalho do mestre falecido, que são os seus comentários ao referido Código, a meu ver um de seus melhores livros.

Em fins de 1928 é Jorge Americano nomeado pelo presidente Washington Luiz para o cargo de procurador geral da Justiça do Distrito Federal, cargo que exerce por dois anos, afastando-se dêle sòmente a 24 de outubro de 1930 , com a vitória da revolução daquêle ano.

A mudança de Jorge Americano, para São Paulo, se o privou de uma situação econômica menos rigorosa que o cargo de chefe do Ministério Público, da Capital da República lhe proporcionava, abriu-lhe, em compensação, a possibilidade de retornar à sua cidade, à profissão de advogado, e, principalmente, à sua Escola.

Com efeito, a transferência para São Paulo o levou ao escritório de advocacia onde militou muitos anos, ao lado de Olegário Pereira de Almeida, grande advogado daqueles tempos, e, mais tarde, ao lado de Agostinho de Arruda Alvim. 
Seu retôrno à Academia, entretanto. só ocorreu em junho de 1931, quando, na qualidade de livre-docente, substituiu Vicente Ráo, que entrara de licença e lhe confiara a regência da cadeira de Direito Civil do $2 .^{\circ}$ ano desta Escola. E o livre docente Jorge Americano deu sua primeira aula nas Arcadas, no dia 1. ${ }^{\circ}$ de junho de 1931.

Nos anos imediatamente seguintes Jorge Americano foi convidado por 4 ou 5 vêzes para substituir catedráticos licenciados.

Para suprir a incerteza dos ganhos vindos dessa atividade e da advocatícia, em que seu sucesso, se bem que apreciável, ainda era recente, o mestre lecionava literatura brasileira no Ginásio São Bento e Direito Civil na Escola de Comércio Álvares Penteado.

Nesse período advem a Revolução paulista de 1932, que encontrou em Jorge Americano, liberal dos mais ardorosos e portanto inimigo intransigente de qualquer regime de fôrça, adepto entusiasta. Logo no início do movimento for ferido, na explosão que ocorreu no Quartel General da Fôrça Pública, em que pereceu o General Salgado. Restabelecido, poucos dias depois organizou, em colaboração com professòres da Escola Politécnica e do Instituto de Higiene, o curso de instrução e aperfeiçoamento para oficiais combatentes voluntários, curso êsse que preparou três turmas antes do fim da luta. Tôda a gente vivia inflamada àquele tempo e Jorgr. Americano, dentro de seu habitual equilíbrio, era dos mais apaixonados!

Decepção e derrota. Luto vestindo a bandeira de 13 listas e invadindo o coração de todos os paulistas.

Terminada a Revolução e aberta, em 1933, a campanha eleitoral para a Assembléia Constituinte, seu nome foi indicado para deputado, pela chapa única "Por São Paulo Unido", composta por tôdas as correntes políticas que representavam o movimento revolucionário. Jorge AMERICANo foi eleito com consagradora votação.

Entre a data da eleição, 3 de maio de 1933, e a da instalação da Assembléia Nacional Constituinte, novembro 
dêsse ano, deu-se o acontecimento mais importante na vida de meu mestre. Realmente, nessa ocasião, fez êle o concurso para a cátedra de Direito Civil desta Academia e foi classificado em primeiro lugar.

Para realçar a importância de tal vitória, convém lembrar que concorreu com Lino de Moraes Leme. A tese que apresentou, trabalho esplêndido sôbre o assunto, se intitulava "Ensaio sôbre o Enriquecimento sem causa". $\mathrm{Na}$ Comissão Examinadora, figuraram, entre outros, VICEnTE Ráo, Filadelfo Azevedo e Virgílio de Sá Pereira.

Em novembro de 1933, ainda sem se haver empossado na cátedra, tão brilhantemente conquistada, muda-se JoRGE Americano, com a família, para o Rio de Janeiro e assume o mandado de deputado por São Paulo, na Assembléia Nacional Constituinte.

Poucos dias haviam transcorrido quando a bancada paulista se reune e aos deputados é feito o comunicado, de que devem votar no ditador, para Presidente do Brasil, em troca de importantes concessões, a serem feitas a São Paulo, no campo político.

Jorge Americano se rebela. Por maior que fôssem as concessões feitas à sua terra, por maior que fôsse o interêsse da Piratininga ainda sangrando da luta, parecia ao deputado de hoje uma incoerência votar no inimigo de ontem, justamente no desempenho de um mandato que lhe fôra outorgado pelo povo vencido, com poderes expressos para atuar contra o vencedor da véspera. Obstinadamente o mestre recusa a dar sua anuência e para não quebrar a unanimidade de um pronunciamento de seus pares, renuncia ali a deputação e retorna a São Paulo. Poucos dias haviam transcorrido entre a data da partida, cheia de esperanças, e o regresso cheio de amarguras.

No dia 21 de fevereiro de 1934 , em sessão solene da Congregação Jorge Americano toma posse do cargo de professor Catedrático de Direito Civil da Faculdade de Direito de São Paulo. Seu grande sonho da mocidade fôra alcançado! 
Aí se inicia uma fase de grande fastígio na sua atividade profissional e de magistério. Ao lado dos trabalhos crescentes do movimentado escritório, onde seus pareceres são muito solicitados e onde é procurado para patrocinar as mais importantes questões, dedica uma parte importante de seu tempo às atividades de classe. Foi, por três vêzes, presidente do Instituto dos Advogados de São Paulo, por várias vêzes Conselheiro da Ordem dos Advogados, Secção de São Paulo, por três anos membro do Conselho Penitenciário do Fstado.

$\mathrm{Na}$ cátedra é professor exemplar, de assiduidade excepcional e incansável dedicação. Lembro-me de minha primeira lição nesta casa, ministrada pelo saudoso mestre. Março de 1935! No meio dos gritos ameaçadores dos veteranos, sequiosos do sangue dos calouros, ouve-se a palavra elegante do elegante mestre a explicar o conceito de direito. A clareza da exposição cativa os compenetrados estudantes e a simpatia afetuosa do professor, ao fim da aula, devolve a seus discípulos um pouco de tranqüilidade que a grita vinda de fora havia roubado.

Vice-Diretor da Academia, exerceu a Diretoria em vários períodos, nos anos de 1938 e 1939. Nesse último ano foi, interinamente, Reitor da Universidade de São Paulo.

Sua carreira, no magistério, entretanto, atinge o ápice, no ano de 1941, em que é nomeado para a Reitoria da Universidade. Falando por ocasião de sua morte, o atual reitor em exercício, apontou um fato que retrata bem a gestão Jorge Americano, à frente da Universidade Paulista. Recebendo-a quase que apenas projetada, engatinhando apenas, traçou-lhe a estrutura, cujas principais linhas ainda a norteiam. Em sua gestão foi projetada a cidade universitária. Entusiasmou-se o mestre com o plano e lembro-me ainda de que certa feita, a pedido do consul americano, acompanhei ao Gabinete do Reitor um professor da Universidade de Colúmbia, que o queria conhecer. Ambos, extremamente interessados no problema do ensino superior, conversaram durante mais de hora diante a maquette da 
cidade universitária, meu mestre empolgado com o futuro da organização, que, em seu espírito, já via como realidade iminente. Aliás, as questões que a universidade suscitava em seu espírito se encontram em seu livro "A Universidade de São Paulo, Dados, Problemas e Planos".

Contemporânea dêsse periodo é a idéia dos fundos Universitários de Pesquisa, dos quais foi presidente de 1941 até 1947. Destinava-se essa organização a ajudar o esfôrço de guerra do Brasil, utilizando o talento científico dêste país, reunido nos laboratórios universitários, para projetar e aconselhar as fôrças armadas brasileiras no campo da ciência. Os resultados alcançados foram enormes e a gratidão da Marinha Nacional se refletiu na outorga da Medalha do Mérito Naval a Jorge Americano, no ano de 1945. No ano seguinte, o presidente dos Fundos Universitários de Pesquisa recebia do Govêrno da República a medalha Rio Branco.

A morte de sua querida espôsa, seguida de moléstia cardiaca de grande seriedade, o afastamento voluntário da Reitoria que de um certo modo o separou de sua querida universidade, baquearam, por um pouco de tempo, o denodado lutador.

Volta êle a seu curso, a seu escritório, a seus estudos, mas sente-se em seu gesto uma certa amargura, um certo desencanto. Seus escritos literários revelam o ceticismo contrastante com o entusiasmo de alguns anos, e o mestre, como que cansado, procura na pintura, na música, em viagens, um descanso das lutas passadas.

Uma última aventura o tira da indiferença. a criação da Faculdade de Direito da Universidade Mackenzie da qual vai ser o Fundador e primeiro Diretor. Ei-lo de nôvo inteiramente em ação escolhendo o corpo docente, fiscalizando os primeiros vestibulares, lecionando, criando a Representação no Conselho Universitário, lutando para estabelecer um ambiente cultural onde a idéia de autonomia universitária florescesse, e o ensino do direito fôsse excelente. Em poucos anos teve sucesso e aquela escola, 
surgida sob o prestígio de seu nome, firmou-se e se tornou respeitada, porque os padrões fixados por Jorge Americano, de seriedade no ensino, de rigor nas aprovações e na seleção dos candidatos, ficaram indelèvelmente marcados naquela Faculdade, que dêsse modo segue a senda traçada por seu fundador.

Todavia, desavindo-se com a direção do Instituto Mackensie, por divergência em questão de princípio, afastou-se c mestre da direção daquele estabelecimento e da cátedra que lá lhe pertencia. Saíu magoado dêste embate, como saíra ferido de muitos outros, em que lutava desinteressadamente por um ideal, que ficava, a seu ver, inatingido, pela renitência da posição contrária.

Aposentado nesta casa, afastado da outra escola, cansado para enfrentar as lides forenses, o intelectual Jorge Americano, homem pobre depois de tanto sucesso, se recolhe à casa e vai viver seus últimos anos com uma dignidade inescedível, dedicando-se, de início, a crônica de sua cidade, depois ao achego da família, com suas queridas irmãs, suas netas, seus parentes amados e uns poucos amigos.

Sua conversa continua viva e espirituosa, seu porte elegante e seu trato da maior afabilidade. As cicatrizes ganhas em cinqüenta anos de luta não aparecem na prosa do homem educado, e as mágoas porventura colhidas nesse interregno são escondidas cuidadosamente na discreção de um viver comedido. A saúde lhe falta, as pernas estão mais fracas e o entusiasmo pela vida diminui.

Sete de dezembro de 1968. Almoçamos juntos; conosco estava o jovem colega e ilustre professor Moreira Alves que testemunhou o fato. Jorge Americano num momento se inflama ao desfiar uma série de história desta casa. É de nôvo o "causeur" encantador ao falar da sua academia. Dois dias depois um derrame o baqueia. Semi-paralisado durante dois mêses, o mestre é libertado pela morte a 6 de fevereiro passado, sem se dar ao trabalho de lutar pela vida. Grande perda sofremos todos nós! 
Revendo, em rápidos traços, essa grande vida, o observador se entusiasma com a figura do jurista, com a imagem do artista, com a marca do pensador. Mas, acima de tudo, o analista se empolga com a figura humana do vulto amado.

Como jurista e escritor do direito um traço há, na obra de Jorge Americano que deve servir de lição para cada autor. É a extraordinária clareza de sua exposição, a limpidez de seu estilo. Não há em sua prosa uma palavra supérflua, como também não há a omissão de um vocábulo necessário. Desprezava qualquer neologismo inútil e a ordem direta, por êle sempre preferida, mostra sua repulsa ao preciosismo, tão do agrado dos escritores medíocres.

Suas idéias resultam sempre de um raciocínio claro, cuja autoridade dispensa a autoridade de outros autores. Que se leiam seus muitos pareceres para a confirmação desta minha assertiva. Em vez de citações e citações, o que se encontra é uma reflexão precisa e irrespondível, alinhada com uma segurança insuperável.

Seus comentários ao Código de Processo Civil são, por igual, reflexo dessa orientação. Econômico na referência a obras alheias, cada artigo é explicado de maneira suscinta e lógica, seu sentido esvaziado pela verruma do analista. O mesmo direi sôbre seus outros livros já antes mencionados.

Parece que a idéia de justiça corre dentro de seu sangue e o orienta na solução dos problemas apresentados. Porque conhecedor dos grandes princípios que informam a sistemática do direito, os conserva tanto no espírito quanto na sensibilidade.

Lembro-me de uma conversa em que de repente, meio em tom de blague, me propôs a seguinte questão:

"Fala-se tanto em princípios gerais de direito que vivo a procurá-los e acho que em tôda minha vida só encontrei dois que realmente se revestissem do indispensável caráter de generalidade. O prin- 
cípio do repúdio à violência e o princípio do respeito a boa fé. Respeitados êsses dois princípios, pode-se estruturar todo um sistema jurídico."

De sua obra literária as crônicas sôbre São Paulo têm um sabor imenso, e de certo constituirão um rico repositório onde o historiador do futuro irá, inexoràvelmente, se abeberar. A primeira série delas, sob o título "São Paulo naquele tempo", por isso que focalizando época mais afastada, têm uma graça cativante, porque é o menino Jorge Americano que vê São Paulo do comêço do século, com olhos de criança, mas o descreve com a pena amadurecida do homem adulto e talentoso.

Por volta de 1950 já um pouco descrente das lutas que enfrentara, o artista Jorge Americano empunhou o pincel. Amador de extraordinários dotes deixa mais de uma centena de quadros. Há coisas boas e más em sua obra, mas dentre aquelas existem realmente muitas excelentes. Além de jogar audazmente com suas côres, seus quadros têm um equilíbrio de composição estranhável em um pintor de fim de semana. Mas, o que revela sua grande sensibilidade é a repulsa, desde logo manifestada, à gratuidade do academismo. êle um criador que repudia a convenção, que rejeita as soluções pré-fabricadas.

Tôdas essas facetas acima aludidas, do advogado, do jurisconsulto, do cronista, do artista, do político, compõem a figura do homem e tiram, do manancial humano que pulsava em seu peito, a fôrça vital que a engrandecia.

Como constantes formadoras de seu caráter, encontramos em Jorge Americano dois traços dominantes. Uma correção de conduta irreversível e uma bondade sem medida.

Ninguém poderia quebrar sua vontade, forçando-o a uma decisão que não fôsse absolutamente correta. A vocação do dever o chamava sempre e nada era capaz de fazê-lo fugir da linha honesta. Em tudo, até nas menores 
coisas, sua intransigente correção se manifestava. Lembrome de fato corriqueiro, que bem demonstra a afirmativa.

Havia o mestre doado sua estupenda biblioteca à Faculdade de Direito da Universidade Mackensie, que a devia retirar dentro de algumas semanas. Por acaso o visitei dias antes, em época que os nossos laços de amizade eram os mais estreitos; examinando seus livros, milhares ainda não relacionados, encontrei um dêles, já esgotado, que debalde vinha procurando adquirir. Alegre, observei:

- Dr. Jorge, o senhor vai dar a biblioteca ao Mackenzie, talvez, pudesse me ceder êsse livro.

Meu interlocutor olhou-me um tanto espantado e respondeu-me:

- Eu não vou dar a biblioteca, eu já dei, os livros não mais são meus!

De outra feita, contou-me que, sendo Procurador Geral do Distrito Federal, foi chamado por um ministro de Estado que lhe pediu simpatia para um caso de uma urna impugnada, que estava aguardando seu parecer. Respondeu-lhe Jorge Americanc que já examinara a hipótese, dera parecer contra o govêrno e não o mudaria. Dias depois, o que não era freqüente, foi convocado pelo Presidente da República. Após as saudações de praxe o Presidente mencionou a questão da urna impugnada, indagando se era realmente convencimento do Procurador Geral ter havido fraude? Jorge Americano redarguiu que sim, aliás já opinara nesse sentido. Mas, como o parecer não fôra ainda encaminhado. o Presidente podia evitar que isso ocorresse, se quisesse substituir o Procurador Geral, pois o cargo continuava à disposição da Presidência. Depois de um segundo de hesitação, o dr. Washington Luiz pediu ao Procurador Geral que encaminhasse o parecer como e quando lhe aprouvesse e o convidou para o chá que estava na iminência de ser servido.

Sua correção e idoneidade só se deixavam igualar por seu grande coração. Amava a humanidade, amava as coisas belas, amava a mocidade que freqüenta esta Escola, amava 
Fac-símile da última recomendação à Faculdade, do Prof. Jorge Americano

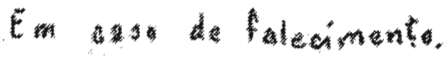

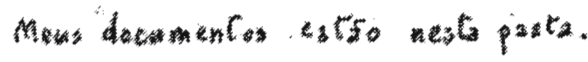

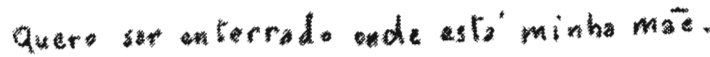

As medatas de mex pai devem ser entregues a Luiz Albarlo.

Avisar men exeritario, tel 352682

Dinction autoras com Dr Marins ou Inr. Arnaldo, na

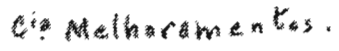

32.4727

Avis Francise Emiggdia Peresca tesoureiro da Fac. de Direito men amiga, que providenciara os funcoras para sairam da Fatuldade, por conta dela, curno é de uso.

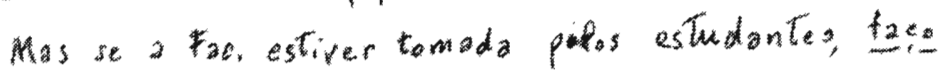
questio de nâs sair de lá, nem que les deem comsentimento, porque um professor, dixo as mato, nato deperde de consentimento dus alunos para entrar ou sair.

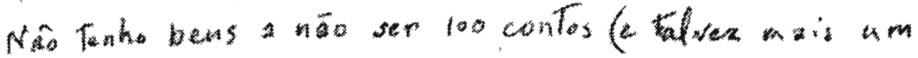

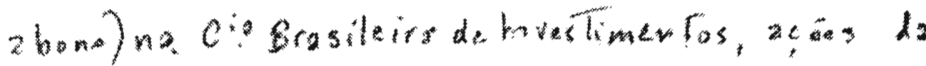
Caboealcis e so contos de um antigunarimo seguro da. Sul America, que vaise raduzindo ano por ano

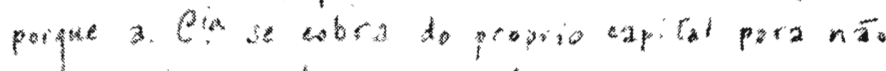
pager mas os aelos innais des avises

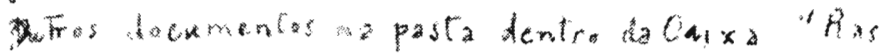
cunhes Divars." 
os seus com uma exuberância que só encontrava paradigma em sua conhecida discreção.

Quanto a seu amor às tradições desta casa, um dos seus últimos pensamentos, antes da doença, foi para elas. Antevendo a morte, escreveu instruções para seu funeral. No bilhete, depois de dar destino às medalhas de seu paj e pedir para ser enterrado ao lado de sua mãe, determina:

“Avisar Francisco Emydio Pereira, (e tel.: 32-4787) tesoureiro da Faculdade de Direito, meu amigo, que providenciará os funerais para saírem da Faculdade, por conta dela, como é de uso. Mas, se a Faculdade estiver tomada pelos estudantes, faço questão de não sair de lá, nem que êles dêm consentimento, porque um professor, vivo ou morto, não depende de consentimento dos alunos para entrar ou sair."

Enorme perda experimenta esta casa com a morte de Jorge Americano! Entretanto a imensidão de seu vulto o alinhará entre as grandes figuras dêste templo, que dêle jamais se separam, e que ficam como fantasmas amigos a perambular por seus vetustos corredores.

Tenho a certeza que se alguém clamar, dentro destas Arcadas, pelo nome de Jorge Americano, de suas sagradas paredes partirá uma voz dizendo:

"Presente". 